\title{
CIRCUMSTANCES AND PROBLEMS OF STREET CHILDREN IN GONDAR CITY ADMINISTRATION: IN A QUALITATIVE STUDY
}

\author{
BISET YALEW ABERA*, BUSHA TAA \\ School of Sociology and Social work Department of Sociology College of Social Science and the Humanities, University of Gondar, Ethiopia. \\ Email: bisetyalew339@gmail.com
}

Received: 23 November 2020, Revised and Accepted: 24 December 2020

\section{ABSTRACT}

Objective: This research aimed to investigate the circumstances and problems of street children in Gondar city administration.

Methods: To achieve the research objectives, qualitative method and Phenomenological design were employed to investigate the daily lived experience of street children. The data were collected by using in-depth interview, FGD and key informants and analyzed thematically. Purposive and snowballing sampling techniques in this study were employed to select participants.

Results: The findings of the study showed that children joined the street due to lack of family planning, divorce, parental detachment, poverty, abuse, and neglect, socio- cultural issues and peer pressure. They are encountered rape, inadequate basic needs social exclusion, and health problems and inaccessibility of health services.

Conclusion: Street children additionally face more troubles once they are on the street that is surely going to have an effect on their development Keywords: Street children, Circumstances, Problems, Gondar city administration.

\section{INTRODUCTION}

The issue of street children is alarmingly increasing occurrences that have been extended in many countries due to the rapid growth of urbanization and the development of industrialization [1]. Various reasons lead to children living on the street vary from country to country depending on the level of economic development, cultural, traditional setting, institutional intervention, level of social coordination, and peace [2] Thus, street children are emerging due to war, poverty, loss of traditional values, domestic violence, physical and mental abuse, and constitute a marginalized group in most societies. The permanent experience of unforgiving environments and the nature of their lifestyle make them vulnerable to mental, physical, and social, health problems, abuse, and neglected. Hence, street children face many difficulties, living in their living conditions, suffering from hunger, harassment, physical abuse, and deprived of basic services such as education and health care [3].

As indicated by different researchers, street children as a social problem are common in the world and more prevalent in developing countries [4]. To become a street child, there might be several covert and overt reasons [5]. Owing to multifaceted socio-economic, political, and natural situations in Ethiopia, cities are increasing [6]. The reasons which lure children to the street and childhood marginalization in Ethiopia came from complex socio-economic, political, and cultural situations [7]. Due to various correlated circumstances and composite problems, there is a large portion of children living in extreme poverty [8].

\section{General objective}

The general objective of the study is to investigate the circumstances and problems of street children in Gondar city administration.

\section{Specific objectives}

The specific objectives are as follows:

- To investigate the circumstances of street children in Gondar city

- To show the foremost problems facing on street children in Gondar city

\section{RESEARCH METHODS AND PROCEDURES}

For the purpose of achieving the objective of the study, this research used a qualitative research approach. It mainly relies on the idea that meaning is socially constructed by individuals within their world and certainty is neither fixed nor single. To accomplish the desired objective, this study employed phenomenological design to describe the lived experience of street children. It is a way of describing phenomena that exists as an integral part of the world in which we are living [9]. To make the research feasible with the available time, and resources, the researcher employed a phenomenological design with a crosssectional study [10]. To collect relevant data from the primary sources, the respondents have selected through none probability, purposive, and snowball sampling. The researcher used and employed different data collection instruments to get relevant and sufficient data that were needed in the study. Thus, the researcher collected the data using indepth interviews, focus group discussion (FGD), and key informants.

Using the sample size of the study, appropriate data from the respondents obtained as the data reached the point of saturation. There are factors and situations which dictated either inclusion or exclusion in the study during sampling process. The researcher set the inclusion and exclusion criteria to identify the participants of the study. The inclusion criteria include; whose age is from 12 to 17 years old, living on street 1 year and above due to their ability to describe the circumstances of street life experiences.

\section{Data analysis procedure}

The data were analyzed and interpreted thematically following different procedures. Thematic data analysis intended to provide a framework for the analysis of qualitative data and by providing ways to manage themes and data [11] and through using familiarization, transcription, organizing, coding, and themes [12].

The purpose of data quality assurances is to guarantee the trustworthiness of the data by reviewing relevant secondary sources which can be cross-checked, the reliability of the collected data. In this study, the researcher checks the entire interview guides before field, the data thoroughly related, recorded data were cleared, and analyzed systematically. Thus, the procedure of data collection was applied as a strategy of converging data which are vital to get trustworthiness and expand the interpretations of data that were collected and presented through different methods. 


\section{RESULTS}

The sample consisted of 20 children, living on the streets for more than 1 year, who were $12-17$ years of age.

\section{Family related issues}

A variety of family related factors have contributed to the child leaving home. When divorce occurs, it is accustomed that the mother is obligated to fulfill the basic needs of the child. However, the mother is reluctant to fulfill these needs which lead to a high quarrel and conflict between the parents of the child. Due to the lack of care, protection, and unfitness of their children, many children leave home. It makes them suffered due to lack of guidance, and misbehavior mostly reflected within the house as there is no help then they leave home. One child living on the street said:

My father was working in a picket at Gondar factory. And my mother was also hired to bake Injera for different persons. However, my father was always drinking alcohol during his free time, and he has beaten my mom in the evening because he was overtaken the alcohol. After that our parents were divorced, and then we lived with our mother, but she couldn't afford to help us because her income was too small. Then I joined street life which is a miserable life.

There are families who are children have to go out to find food and some end up in the streets. They were forced to depart home and on the street are influenced by the family's relationship in the house. The family relations at home contributed to children's living on the street under very harsh conditions. One participant said as follows:

5 years ago, my parents were divorced. Currently, they are living together, but they always quarrel. The reason for their disagreement was envy while my father is blind, and he always asked for the mother who was with you? This creates abhorrence in me and I distanced myself from my parents. After that, I was forced to live such a miserable life. Since, I left my parents, and I spend gruesome life on the street.

Most children leave home because of a lack of parental affection of children at home. Due to a lack of affection, they decided to leave home. Their parent's disagreement at home is preferred to the street. Thus, due to parented affection, care, and protection, they involved on living on the streets. The lack of affection, care, and maltreatment at home forced them is neglected education and the broad social interaction of the community. FGD participants discuss as follows:

Most of the time the people thought our first arrival on the street caused by economic problems; however, a number of the children left from home due to parental disagreement in the house. It is because the dad disagreed with mom, then children autonomously decided to depart home and started living on the street. Then we spent a miserable life.

Around Gondar the fertility is low and, so the government established a safety net program to mitigate their poverty; however, the women give lots of birth to children and parents migrate with the number of children rural to urban. Safety net program in low income families have led to significant level of parent's migration with children. Parents place greater value on give birth children to get assistance than use family planning. Key informants described the following:

In fact, there are different reasons that have encouraged children living on the street. From those reasons, lack of birth control is provided in wagera, west Blessa, East Belssa, and Kinfaze Begela because safety net program has existed to assist for fewer income individuals depending on the number of families so that they increase their child to get assistance from this program. Then, in one home, a lot of children live and those they couldn't get basic needs as the lands are not fertile.

\section{Economic scarcities}

The vulnerable children living on the street come from their poor family's background. Most families live in overcrowded slum areas of the urban centers and their income is incredibly low. Then, children opted to live on the streets to get better opportunities because there is no money for education. Within the same case, they are influenced by parents to travel to the streets, to seek help. Children who come from a very poor family to stopped going to school to support their families economically. Moreover, parents give greater value to children being employed in economic activities than going to school. One, participant said as follows:

My parents are working on a cereal masher to get a powder. This powder wasn't enough for all family members. We live in a rented house, and we pay 450 birrs; however, we could not pay for the rent on time. Because my parents forced me to start begging, I dropped out of education, and I couldn't continue my education.

There is an association between the onsets of family poverty that complicated life on the street. Children are forced to work without their permission to get little money for their parents. The children have an obligation to do what the parents want that do. Because of poverty at home, the children assumed that there will be an opportunity in urban areas. For children living in families with these problems and, there is inadequate education. Thus, it makes children of poor families end up in towns to search of a more satisfying lifestyle. In this regard one participant said:

My parent's livelihood is agriculture and, yet we couldn't offer our basic needs. We haven't enough land and might not produce and feed the family properly. Then my father hired other farmers in the summer; however, the hired person couldn't provide our basic needs. Moreover, we sold our lands for 2 or 3 years in cash. Two years ago, my parents decided to rent to our uncle and that I hired to keep cows for 1 year. I left home for better working opportunities and to get accessible resources in an urban area.

The problems of poverty in some street children's families forced the child living on the streets as a substitute for their homes. Most rural families are unable to offer economic support to the children. Thus, poverty is the most often because of the reason for the bulk of children to interact in street life. Then children migrated from rural to urban and that they started living on the street. Since, children live in the urban street as the art of survival. Key informant illustrates as follow:

Our institutions always attended street children and as we find most of the street children were coming from lower-income parents. Since, their parents couldn't support them; therefore, the children who live on the street are mainly influenced by the economic problem. Thus, most street children came from the agricultural area because of a lack of basic needs, as their parents couldn't afford their children. Then they migrate from rural to urban areas to get their basic needs.

\section{Socio-cultural issues}

The family is beat their children both physically and social violence is about due to the culture of society. These situations create a fertile ground for a number of street children. Hence, the unwanted activities of children in the given communities, the families become angry who leave home to live on the street. In this regard one participant said:

I was taking some money from home to gambling. And that I returned home late, however, except mother my father failed to know what I was doing. Then I did repeatedly and in an unspecified time, our oxen were vandalized when did gamble. Then my mother told my father, about my gambling, and he beat me with a stick. However, I couldn't leave gambling. Subsequently, all neighbors labeled me as a bad boy due to my gambling. As a result, I had gone to the street and now my life is miserable.

The early marriages for girls help to expand several social and economic benefits to parents and relatives. To escape from poverty, families used their children as traditional functions of finding income. In the culture of the society at large, parents arrange an early marriage for their children, particularly for daughters, in a hidden way without the knowledge of government officials. The cultural system does not function properly about protecting their children affected negatively. Many parents believe that daughters should not continue their education because of the assumption that being exposed to premarital sex and unnecessary pregnancy, which underpins the drop-out of many girls from school to get married. The key informants described as follows: 
Our institution is working with street children. Many street children are forced to early mirage. This early marriage has been routine within the rural family. This had been done still without the permission of children for unknown persons in a hidden way. The parents are also marrying their female to escape from poverty. As well, the parents assume that the daughters will sexually expose that can bring unwanted pregnancy and exposure to sexually transmitted diseases (STD).

\section{Abuse and abandonment \\ Street children are forced by parents who could not consider the future of the child. They might not realize that whether a person is most persuaded by the opposite of what must rely on the knowledge of the future. Children are physically thumped by parents because of the response that the child is making a certain mistake. Thus, due to abusive families, the children cannot find love and care at home, as a result, they left home and living on the street. One participant said the following: \\ My parent's livelihood is cereal trade. When I was a grade 6, I have gone to school infrequently because my father did not allow me to attend daily. This year we changed our rent house and that I have carried TV but it had been broken and my dad is very sad and beaten me with a stick. Consequently, I was to interrupt and came to Gondar in the piazza. Then I began to live on the street with no kindness.}

\section{Health problems}

The health condition of street children in Gondar city is very problematic. Many streets children suffer from malaria; diarrheal, TB, and AIDS as, they live in unclean surroundings dirty, and with a number of other environmental hazards. The street children lack basic needs and access to health institutions within the study. Due to the lack of health service, safe sleeping areas, and food, they are in danger of health problems. Consequently, children face health difficulties and a lack of health services access. One participant said as follows:

After I started living on the street, yes, the health problems encountered me. Those health problems are coming from multiple directions. Among those, lacks food, poor sanitation of the sleeping area, and the lack of clinical treatments. Once I fall and my leg slashed, however, I couldn't get clinical treatment on time. Although I hoped to get clinical treatment, it took a long time to travel to the hospital.

Due to eating patterns of street children, there were different diseases facing them because it is dependent leftovers from hotels and garbage bin. Due to the labeling of street children as thieves, they are chased by workers of the hotel during search leftover. Along with this, they could not get leftovers, and then they were exposed to disease easily. A street child articulated as follows:

After I started living on the street, I become hungry. Subsequently, I went to hotels to find leftover foods. Due to improper feeding systems and eating leftover foods, I was exposed to disease, diarrhea and I was not getting any medical treatment.

The street children could be in any health problem due to lack keep their basic hygiene. A lack of sanitation and drinking dirty water contribute to poor health. Due to sleeping on the veranda, they are constantly exposed to harsh climates such as intense sun, rain, and cold. Therefore, they are the neglected group of societies and do not have the capacity to requisite function. The failure to make an appropriate source of income and a helpful environment has an undesirable effect on health. Due to sleep at the roadside, they raped at night. They suffered from STD like HIV AIDS in the cities, because they sleep together. This disease follows from inadequately targeted health service provision for the vulnerable group of individuals within the study area. FGD discussant articulated as follow:

It is because we have not given credit for our hygiene while we have not taken a bath and drink dirty water that contributed to our health difficulty. Furthermore, they have not placed to sleep; therefore, we are sleeping outdoors. The foremost serious unhealthiest is that they have no income.
Sleeping, and working conditions are causes for street children uncovered by health difficulties. Furthermore, due to the rape of street girls, we face unwanted pregnancies and giving birth. When we are exposed to sex-related vulnerability, there are challenges facing them such as unsafe abortions and sicknesses associated with pregnancy.

\section{Inadequate basic needs}

Because of insufficient basic needs, most of the street children have developed means of finding food in different hotels. However, not all street children obtained leftovers from hotels. The beggars who are baby and female get something more of emotion and pity for them. They are perceived beggars who are female and baby on the street priority. Furthermore, there are gender differences and ages that verify the streets to beg on the street. The opportunities made available to those who make it more appealing to others. Although, children are a pillar of the country and the backbone of society, their livings are insecure. More importantly, society perceived them as a threat to the city. It makes children psychologically damaged and feels humiliated. In this regard, a street child illustrated as follows:

After starting to live on the street many problems encountered me. Among these problems insufficient, basic needs are the foremost disturbing for me. This made it hard to get food easily through begging because my age was the most determining factor. The beggars who are female and baby get something more pity. As well, I sleep on the street corner because I have no shelter. However, they chased me as the societies assume street children are the troublemaker and threats to the city.

The street child suffers from drinkable water, food, and shelter. Lack of basic needs forcing those unwanted activities, they involve in criminal activities like picking pocket, to survival their life. This is because the experiences of street children in relation to basic needs can be forcing into unwanted activities. The negative perception of societies toward street children is the fundamental cause for most inadequate basic needs even leftover. Key informants illustrated as follows:

As concerned bodies, we assess them infrequently. From our visits, we could identify their problem in street life. Thus, without any hesitation, they actually exposed to communicable diseases. Moreover, due to inadequate basic needs, they involve in unwanted activities such as picking pocket and burglary. Their activities lead a negative perception by societies.

\section{Abused and neglected}

The parents' beating of their children made live on the street. The street children are badly treated by securities in the city. In this regard one participant said:

When I came to Gondar for the first time, the police endeavoured to take me back to my parents. They harassed me through insult and that they wanted me to return to my parents by force. However, I was not interested to return in my parents. Thus, their attempt did not add up due to my parents' abuse.

The people are misinterpreting the problems of the street children, and they end up in exclusion. They lose the value of their existence and could not take their personal hygiene, therefore, society excluded them. Lack of affection makes their life full of challenge. As a result, they could not get help from society to survive. One street child said as:

Various problems faced with me on street. From those, social exclusion is taking the biggest share. The reason, I was excluded from societies is that I've not cared for my personal hygiene. As well, society could not understand why I live on the street. Obviously, I couldn't care about my personal life due to lack of access and that I only give priority to food.

\section{DISCUSSION AND CONCLUSION}

The results of the analysis imply that there are different reasons for children living on street in Gondar city administration. Regarding these, most findings of scientific studies conducted on the street children so far are well-matched. This was done in accordance with the aims 
of the study outlined. For instance, a study finding of family related issues investigated by Njeru [13] absolutely found that due to the lack of standard income, many street children leave home to address basic demands. Because the family has failed, it is crucial that children providing basic needs, for them. Furthermore, a study conducted by Densely and Joss [14] found that several families disintegration, the proportion of street children in urban areas has reached alarming proportions. Vergara et al. [15] conducted a study showing parenting detachment within the home is elements that push children into the streets because of poor relations. These findings are consistent with this study, which identified family problems as major reason for children living on the street. Thus, it articulated that almost all of the children were not given sufficient food and that they decided to go away. These findings are consistent with this study, which identified family problems as a major reason for children living on the street. Thus, it articulated that almost all the children were not given enough food and that they decided to go away. Similarly, to a particular extent, the children who made their decision living on the street were forced by parents' disagreement and divorce. Unlikely with pervious researches, this study found that lack of birth control/ family planning and establishments of safety net programs forced children to leave home. Thus, this study finding the establishments of safety net programs and the assistance of a low-income group of societies from the safety net program in lower-income families were not using birth control.

Furthermore, the study conducted by Diriba [4] indicated that there are street children who do not have shelter in the city. They sleep the pipe, on the street, and abandoned building. They are terribly vulnerable to physical attack and grievance that exposed them to health problems. However, this study found that the he working conditions, living conditions, eating systems, access to health services, and bureaucracy of help organizations were faced on street children. Furthermore, this study found that most social problem that face is negligence such as threats, insulting, strike, and stealing of personal properties by members of the public right away. Thus, it is inconsistent with other former studies. Furthermore, they are perpetually exposed to harsh weather such as intense sun, rain, and cold. Physical assault is common and younger boys are overwhelmed by older boys or gang members, and that they beat. Therefore, they are vulnerable cluster of societies.

From the finding of the study, the following conclusion is warranted. The street children are compelled by pull and push factors. Consequently, this study shows that the prevalence of street children could be the result of the complicated interaction of divorce, parental detachment, and lack of families, poverty, cultural factors, peer pressure, and improper-usage of children by parents. There are specific issues that were connected to children's experiences on the street. Thus, children living on the street faced abused and neglected, health issues, social exclusion, and violence by police. Street life exposes children to a variety of experiences which can disrupt their world-view and image of reality.

\section{ACKNOWLEDGMENTS}

We would like to thanks MasterCard found scholar program to covered the expenses of this research.

\section{FUNDING}

We are very grateful thanks MasterCard foundation scholars' program at University of Gondar for covering expenses of this research.

\section{REFERENCES}

1. Lindenberg MB. Going Global-Transforming Relief and Development NGOs. United States: Kumarian Press, Inc., MGLSD

2. Kibrom B. Life in the Streets of Adama: The Situation of Street Children in a Fast-growing Ethiopian Town MA Thesis. Ethiopia: Addis Ababa University; 2008.

3. Hecht T. At Home in the Street: Street Children of Northeast Brazil. Cambridge, UK: Cambridge University Press; 2003.

4. Diriba T. Contributing Factors to Streetism and Life Condition of Street Children: The Case of Nekemete Town MA Thesis. 2012.

5. Bondo A. Causes, Survival Strategy and Societal Perception an Empirical Study of Street Children in Kathmandu MA Thesis. Norway: University of Nordland; 2014.

6. Kebede SK. The Situation of Street Children in Urban Centres of Ethiopia and the Role of NGO in Addressing their Socio-economic Problems: The Case of Hawassa City. 2015.

7. Tatek A. Šik'älla: The Survival Strategies of Ethiopian Child Beggars: Proceedings of the International Conference of Ethiopian Studies, Harald Aspen. Norway: Norwegian University of Science and Technology; 2009.

8. Boafo A. Livelihood Strategies of Street Children in Accra, PhD Dissertation Presented. Ghana: University of Ghana; 2015.

9. Astalin PK. Qualitative Research Designs: A Conceptual Framework. Grounded Theory: Practical Guide for Management. North Gondar: Women and Children Affaires Directive; 2019.

10. Astalin PK. Qualitative Research Designs: A Conceptual Framework. Grounded Theory: Practical Guide for Management. New York: Business and Market Researches Sage Publication Ltd.; 2013.

11. Bryman A. Social Research Methods. New York: Oxford University Press Inc.; 2008.

12. Lacey A. Qualitative Data Analysis. United States: Sage Publication Ltd.; 2007.

13. Njeru JW. Situation Analysis for Children in Difficult Circumstances. Mombasa: Congress Proceedings Report; 1989.

14. Densely MK, Joss DM. Street children: Causes and consequences, and innovative treatment approaches. Work 2000;15:217-25.

15. Vergara E, Meneses P, García P, Aburto L. Metropolitan observatory for street children and youngsters: A Chilean experience of an innovative model. J Appl Res Child 2013;4:1-23. 